\title{
Effect of circulating 25-hydroxyvitamin D and antioxidant capacity level on cognitive function parameters of children with idiopathic short stature
}

\author{
Omyma G. Ahmed ${ }^{1}$, Hala M. Sakhr ${ }^{2 *}$, Haytham M. Ali ${ }^{3}$ and Lamiaa Abdlsamiee ${ }^{3}$
}

\begin{abstract}
Background: An optimal level of vitamin $D$ is necessary for normal bone growth. Recently, vitamin $D$ has been linked to many neurological disorders, changes in antioxidant capacity levels, and cognitive function decline in old age; thus, the aim was to evaluate the effect of vitamin D and antioxidant levels on the cognitive function parameters of children with idiopathic short stature (ISS).

Results: A prospective case-control study was conducted with 60 primary school-aged children with ISS who were compared to 60 unrelated healthy age- and sex-matched children as a control group. A complete clinical evaluation; anthropometric measurements; neurocognitive function parameters using the Stanford-Binet test, fifth edition; vitamin D level; total antioxidant capacity (TAC); total oxidative stress (TOS); and oxidative stress index (OSI) were measured. A total of $83.3 \%$ of children with ISS had a vitamin D level $<30 \mathrm{ng} / \mathrm{ml}$ with significantly lower vitamin D levels than the control group. The TAC level was significantly lower in children with ISS than in healthy children. Children with ISS had an average level for all of the cognitive function parameters but a lower non-verbal IQ, full-scale IQ, fluid reasoning, knowledge, quantitative reasoning, and working memory than healthy controls. A positive correlation was found between vitamin D level and all anthropometric measurements, all IQ parameters, and TAC levels in the studied children. A positive correlation was found between TAC and all IQ parameters.
\end{abstract}

Conclusion: Vitamin D level and antioxidant capacity level have a major impact on cognitive function parameters in children with ISS.

Keywords: Vitamin D, Idiopathic short stature, Antioxidant capacity, Cognitive functions

\section{Background}

Vitamin $\mathrm{D}$ is an important fat-soluble vitamin that is required for bone health and calcium homeostasis [1]. Vitamin D has a well-recognized role in bone formation, skeletal growth, development, and normal bone mineralization [2-4]. Vitamin D deficiency may negatively affect bone mineralization during childhood [5].

Idiopathic short stature (ISS) in children is a clinical description of a child with a height of more than 2 standard deviations below the corresponding mean height for their

\footnotetext{
* Correspondence: halasakhr@yahoo.com; hala.sakhr@med.svu.edu.eg ${ }^{2}$ Department of Pediatrics, Faculty of Medicine, South Valley University, Qena, Egypt

Full list of author information is available at the end of the article
}

age and sex, without evidence of a cause and with a normal stimulating growth hormone test [6-8].

Vitamin D deficiency is a major public health problem, and vitamin D deficiency and insufficiency are also common in sunny areas such as Asia-Pacific, Africa, and Middle East regions [9, 10]; the estimated prevalence rates of levels less than $30 \mathrm{ng} / \mathrm{ml}$ in the USA, Turkey, Iran, and India were $47 \%, 89 \%, 93 \%$, and 99\%, respectively [10], while Cashman et al [11] estimated that vitamin D deficiency with levels less than $20 \mathrm{ng} / \mathrm{ml}$ in the European population had a prevalence of $40.4 \%$.

Vitamin D deficiency, in addition to its wellestablished musculoskeletal effects, is linked to and associated with the development and progression of many 
different neurological disorders [12]. Experimental studies have shown that active vitamin D may influence the brain and neuronal development and have neuroprotective and antioxidant effects [13]. The widely distributed vitamin D receptors (VDR) in the brain [14] and the ability of the brain to synthesize active vitamin D locally are highly suggestive of its involvement in the normal development and function of the brain [15].

The aim of this current study was to evaluate vitamin D levels and oxidative stress levels in children with ISS and to evaluate their effect on cognitive function parameters of children with ISS.

\section{Methods}

\section{Study design}

A prospective case-control study was conducted with 60 school-aged children 6-12 years of age who were seen as outpatients at the pediatric endocrinology clinic from January 1, 2018, to December 31, 2018. These children were compared to 60 healthy age- and sex-matched children as a control group. We adjusted the size of the sample to achieve $80 \%$ power and $5 \%$ confidence of significance (type 1 error). All participants were informed about the aim of our study, and written informed consent was obtained from their parents after approval of the ethics committee.

\section{Patient evaluation}

A detailed history of age, sex, residence, nutritional history, family history, history of musculoskeletal pain, chronic fatigue, and headache was obtained.

Height was measured by a standard stadiometer to the nearest $0.1 \mathrm{~cm}$. Weight was measured by an electronic scale to the nearest $0.1 \mathrm{~kg}$. Body mass index (BMI) was calculated as $\mathrm{kg} / \mathrm{m}^{2}$. All anthropometric measurements were then expressed as $Z$ scores (standard deviation scores), which express the anthropometric value as a number of standard deviations or $Z$ scores below or above the reference mean or median value, which was calculated from the following formula [16]:

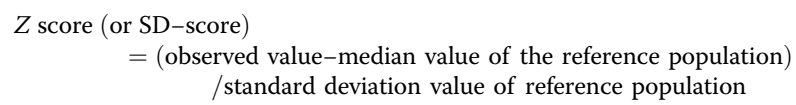

Cases had ISS with a height $>2$ SD below the corresponding mean height of a given age, sex, and population group without evidence of systemic, endocrine, or chromosomal abnormalities and normal stimulated growth hormone (GH) levels [6].

Complete cardiac, respiratory, abdominal, and neurological examinations of the patients were performed with the exclusion of cases with a chronic parasitic infestation, severe anemia, chronic disease as thyroid, celiac disorders, or inflammatory bowel disease. Cases suspected to have chromosomal disorders, cases with neurological disorders, and children who were taking vitamin D supplements in the last 3 months were also excluded.

Bone age (BA) was determined by the radiograph of the left hand and wrist according to the method of Greulich and Pyle [17].

\section{Cognitive assessment}

Neurocognitive functions were evaluated using the Arabic version of Stanford-Binet test [18], the fifth edition, which is a standardized and well-validated psychometric test used to evaluate intelligence quotient (IQ) level (non-verbal, verbal, and full-scale IQ), fluid reasoning, knowledge, quantitative reasoning, visuospatial skills, and working memory.

\section{Laboratory workup}

Blood samples were collected into two empty and anticoagulated tubes containing ethylene diamine tetraacetic acid (EDTA). The serum was then separated from the cells by centrifugation at $3000 \mathrm{rpm}$ for $10 \mathrm{~min}$. Serum samples for measurement of serum $25(\mathrm{OH})$ D3, total oxidative stress (TOS), and total antioxidant capacity (TAC) levels were stored at $-80^{\circ} \mathrm{C}$ until they were used.

\section{Vitamin D assessment}

The assessment of vitamin D was conducted using a commercially available sandwich enzyme-linked immunosorbent assay (ELISA) kit supplied by Chongqing Biospes Co., Ltd. (Chongqing, People's Republic of China) with the catalog number BYEK1472 using a microplate ELISA reader (EMR -500, USA). Vitamin D deficiency was defined as a 25-OHD level of $\leq 20 \mathrm{ng} / \mathrm{ml}$ and vitamin D insufficiency as 21 to $29 \mathrm{ng} / \mathrm{ml}$ and normal level as $\geq 30 \mathrm{ng} / \mathrm{ml}[19]$.

\section{The TAC and TOS levels}

The TAC and TOS levels were evaluated spectrophotometrically using a commercially available colorimetric assay kit supplied by Bio-Diagnostic Co. Cairo, Egypt, catalog no. TA 2513.

The level of TAC $<1 \mathrm{mmol} / \mathrm{L}$ was considered too low, 1-1.3 mmol/L indicated a borderline level and TAC > $1.3 \mathrm{mmol} / \mathrm{L}$ showed sufficient antioxidant capacity [20].

\section{Determination of the OSI}

The ratio of TOS to TAC was accepted as the Oxidative Stress Index (OSI). The OSI value was calculated according to the following formula: OSI (arbitrary unit) $=$ TOS $\left(\mu \mathrm{mol} \mathrm{H}_{2} \mathrm{O}_{2}\right.$ Eq/l)/TAC (mmol Trolox Eq./L) $\times 100$ [21].

\section{Statistical analysis}

Data analysis was performed using SPSS version 20 (Statistical Package for Social Science). Data are presented as a number, percentage, mean, and standard 
deviation. A chi-square test was used to compare qualitative variables. Independent $t$ tests were used to compare quantitative variables between the two groups. Pearson correlation was performed to measure the correlations between quantitative variables. $P$ values were considered statistically significant when $P<0.05$.

\section{Results}

This current study included 60 children with ISS with a mean age of $10.16 \pm 1.98$ years: 32 males (53.3\%) and 28 females (46.7\%). These children were compared to 60 healthy age- and sex-matched children as a control group, with a mean age of $10.23 \pm 1.54$ years: 34 males (56.7\%) and 26 females (43.3\%). There were no significant differences between the two groups with regard to age or sex (Table 1).

All anthropometric measurements were significantly different between patients and controls; the patients' weight, height, and BMI were $(23.46 \mathrm{~kg} \pm 6.17,120.83$ $\mathrm{cm} \pm 12.4$, and $\left.16.0 \mathrm{~kg} / \mathrm{m}^{2} \pm 3.16\right)$ versus the control group $(33.7 \mathrm{~kg} \pm 7.68,138.43 \mathrm{~cm} \pm 9.12$, and $17.36 \mathrm{~kg} /$ $\mathrm{m}^{2} \pm 2.14$, respectively) (Table 1 ).

The vitamin D level in the ISS group $(20.63 \mathrm{ng} / \mathrm{ml} \pm$ $7.35 \mathrm{SD}$ ) was significantly lower than that in the control group $(32.18 \mathrm{ng} / \mathrm{ml} \pm 9.2 \mathrm{SD})$. There was also a significant difference between the two groups with regard to the percentage of children with vitamin D deficiency and insufficiency, with 28 children (46.7\%) and 22 children (36.6\%) in the ISS group having vitamin D deficiency and insufficiency, respectively (total 50/60 children $83.3 \%$ ), while 22 children (36.7\%) in the control group had only vitamin D insufficiency, and no one in the control group had deficiency (Table 1).

The TAC level was significantly lower in the ISS group $(1.50 \mathrm{mmol} / \mathrm{L} \pm 0.6 \mathrm{SD})$ than in the control group (2.27 $\mathrm{mmol} / \mathrm{L} \pm 1.31 \mathrm{SD})$. OSI was significantly higher in the ISS group $(21.1 \pm 12)$ than in the control group (17.94 \pm 14.77), while there was no significant difference in TOS between the two groups (Table 1).

The cognitive function parameters of ISS children were within the average range of IQ classifications [18], but nonverbal IQ (98.9 \pm 8.85$)$, full-scale IQ (102.13 \pm 7.43$)$, fluid reasoning (99.47 \pm 10.65$)$, knowledge (101.26 \pm 7.96$)$, quantitative reasoning $(105.9 \pm 7.51)$, Visuospatial $(101.83 \pm 7.9)$, and working memory $(99.13 \pm 8.7)$ were significantly lower than in the control group with $P$ values $<0.05$ (Table 2).

Children with ISS and vitamin D deficiency in comparison to ISS children without deficiency had significantly lower non-verbal IQ $(97.54 \pm 9.36)$, full-scale IQ (101.08 \pm 7.71), knowledge (99.92 \pm 7.97$)$, quantitative reasoning $(104.54 \pm 7.47)$, visuospatial $(100.54 \pm 8.22)$, and TAC $(1.36 \mathrm{mmol} / \mathrm{L} \pm 0.57)$ with $P$ value $<0.05$ and without significant difference as regard total oxidant status and oxidative stress index with $P$ value $>0.05$ (Table 3).

There was a positive correlation between vitamin $\mathrm{D}$ level and weight $Z$ score $(r=0.581, P=0.000)$, height $Z$ score $(r=0.588, P=0.000)$, and BMI $Z$ score $(r=0.325$, $P=0.011)$ in the studied children (Fig. 1a-c).

There was a positive correlation between vitamin $\mathrm{D}$ level and all cognitive function parameters: non-verbal IQ $(R=0.474, P=0.000)$, verbal IQ $(r=0.327, P=$ $0.011)$, full-scale IQ $(r=0.446, P=0.000)$, fluid reasoning

Table 1 Characteristics data of the studied groups

\begin{tabular}{|c|c|c|c|}
\hline Variable & $\begin{array}{l}\text { Patients with ISS } \\
N=60\end{array}$ & $\begin{array}{l}\text { Control } \\
N=60\end{array}$ & $P$ value \\
\hline Age (years) & $10.16 \pm 1.98$ & $10.23 \pm 1.54$ & 0.83 \\
\hline Sex & $\begin{array}{l}32(53.3 \%) \text { male } \\
28(46.7 \%) \text { female }\end{array}$ & $\begin{array}{l}34(56.7 \%) \text { male } \\
26(43.3 \%) \text { female }\end{array}$ & 0.71 \\
\hline Weight (kg) & $23.46 \pm 6.17$ & $33.7 \pm 7.68$ & $0.0001^{* *}$ \\
\hline Weight $z$ score & $-2.63 \pm 1.33$ & $-0.078 \pm 0.72$ & $0.0001^{* *}$ \\
\hline Height (cm) & $120.83 \pm 12.4$ & $138.43 \pm 9.12$ & $0.0001^{* *}$ \\
\hline Height z score & $-3.0 \pm 0.86$ & $-0.23 \pm 0.86$ & $0.0001^{* *}$ \\
\hline $\mathrm{BMI}\left(\mathrm{kg} / \mathrm{m}^{2}\right)$ & $16.0 \pm 3.16$ & $17.36 \pm 2.14$ & $0.006^{*}$ \\
\hline BMI z score & $-0.89 \pm 1.62$ & $0.05 \pm 0.76$ & $0.0001^{* *}$ \\
\hline Vit D (ng/ml) level & $20.63 \pm 7.35$ & $32.18 \pm 9.2$ & $0.0001^{* *}$ \\
\hline Percentage of vitamin D deficiency \% & $50(83.3 \%)$ & $22(36.7 \%)$ & $0.0001^{* *}$ \\
\hline TAC (mmol/L) & $1.50 \pm 0.6$ & $2.27 \pm 1.31$ & $0.0001^{* *}$ \\
\hline TOS $(\mu \mathrm{mol} / \mathrm{L})$ & $0.29 \pm 0.19$ & $0.27 \pm 0.19$ & 0.57 \\
\hline OSI & $21.1 \pm 12$ & $17.94 \pm 14.77$ & 0.20 \\
\hline
\end{tabular}

ISS idiopathic short stature, BMI body mass index, TAC total antioxidant capacity, TOS total oxidant status, OSI oxidative stress index *P value $<0.05$

${ }^{* *} P$ value $<0.001$ 
Table 2 Cognitive function parameters in studied groups

\begin{tabular}{llll}
\hline Variable $($ mean \pm SD) & Patients $(N=60)$ & Control $(N=60)$ & $P$ value \\
\hline Non-verbal IQ & $98.9 \pm 8.85$ & $106.78 \pm 7.8$ & $0.0001^{* *}$ \\
Verbal IQ & $104.36 \pm 8.3$ & $106.52 \pm 9.43$ & 0.186 \\
Full-scale IQ & $102.13 \pm 7.43$ & $107.19 \pm 8.21$ & $0.0006^{* *}$ \\
Fluid reasoning & $99.47 \pm 10.65$ & $105.56 \pm 8.15$ & $0.0006^{* *}$ \\
Knowledge & $101.26 \pm 7.96$ & $106.82 \pm 11.49$ & $0.003^{*}$ \\
Quantitative reasoning & $105.9 \pm 7.51$ & $109.52 \pm 9.86$ & $0.025^{*}$ \\
Visuospatial & $101.83 \pm 7.9$ & $105.19 \pm 6.62$ & $0.012^{*}$ \\
Working memory & $99.13 \pm 8.7$ & $107.2 \pm 8.42$ & $0.0001^{* *}$ \\
\hline
\end{tabular}

IQ intelligence quotient

${ }^{*} P$ value $<0.05$

**P value $<0.001$

( $r=0.346, P=0.007)$, knowledge $(r=0.363, P=0.004)$, quantitative reasoning $(r=0.350, P=0.006)$, visuospatial processing $(r=0.340, P=0.008)$, and working memory $(r=0.504, P=0.000)$ (Table 4$)$.

There was a positive correlation between TAC level and all cognitive function parameters: non-verbal IQ $(R$ $=0.737, P=0.000)$, verbal IQ $(r=0.691, P=0.000)$, fullscale IQ $(r=0.769, P=0.000)$, fluid reasoning $(r=$ 0.697, $P=0.000)$, knowledge $(r=0.691, P=0.000)$, quantitative reasoning $(r=0.615, P=0.000)$, visuospatial processing $(r=0.644, P=0.000)$, working memory $(r=$ $0.653, P=0.000)$, and a negative correlation between OSI and all cognitive function parameters (Table 4).

There was a positive correlation between vitamin D levels and TAC $(r=0.546, P=0.000)$ and a negative correlation with OSI $(r=-0.0317, P=0.014)$, but we could not demonstrate a correlation between the vitamin D level and total oxidative stress level (Table 4).

\section{Discussion}

An adequate level of vitamin D has been known for its positive impact on bone metabolism and bone turnover [22-25] and is required to achieve normal genetic growth potential among children [26]; vitamin D deficiency has become very common in both children and adults [27]. Zhu et al. [28] showed that $40 \%$ of schoolaged children had vitamin D levels of $20 \mathrm{ng} / \mathrm{ml}$, and Roh et al. [29] demonstrated that vitamin $\mathrm{D}$ deficiency in children aged 6 to 12 years is very common, with $59.1 \%$ in his study found to have vitamin D deficiency. In the current study, we found that $36.7 \%$ in the healthy children group had vitamin D insufficiency, while $46.7 \%$ and $36.6 \%$ in the ISS group had vitamin D deficiency and insufficiency, respectively.

The effect of vitamin D level on growth was demonstrated in different age groups, and multiple studies demonstrated that vitamin D status affects growth outcome and is associated with stunted growth in the pediatric age group $[22,30,31]$. Liu et al. [32] revealed a positive correlation between serum $25(\mathrm{OH}) \mathrm{D}$ concentration and BMI-for-age $Z$ score in school-aged children. Miguel [33] stated that serum levels of vitamin D varied significantly between different BMI groups with the lowest levels in individuals with either high or low BMI, demonstrating a curvilinear, U-shaped association. The current study revealed that children with ISS had significantly lower weight, height, and BMI than healthy children and

Table 3 Cognitive functions and oxidative stress parameters among children with idiopathic short stature subgroups with and without vitamin D deficiency

\begin{tabular}{lll}
\hline Variable (mean \pm SD) & ISS with vitamin D deficiency $(N=50)$ & ISS without vitamin D deficiency $(N=10)$ \\
\hline Non-verbal IQ & $97.54 \pm 9.36$ & $104.33 \pm 2.73$ \\
Verbal IQ & $103.54 \pm 8.57$ & $107.67 \pm 6.71$ \\
Full-scale IQ & $101.08 \pm 7.71$ & $106.33 \pm 4.50$ \\
Fluid reasoning & $98.67 \pm 11.77$ & $102.67 \pm 2.25$ \\
Knowledge & $99.92 \pm 7.97$ & $106.67 \pm 5.68$ \\
Quantitative reasoning & $104.54 \pm 7.47$ & $111.33 \pm 5.09$ \\
Visuospatial & $100.54 \pm 8.22$ & $107 \pm 3.22$ \\
Working memory & $98.5 \pm 8.99$ & $101.67 \pm 7.6$ \\
TAC (mmol/L) & $1.36 \pm 0.57$ & $0.045^{*}$ \\
TOS ( $\mu$ mol/L) & $0.3 \pm 0.15$ & $0.025 \pm 0.47$ \\
OSI & $21.26 \pm 11.65$ & $0.4 \pm 0.27$ \\
\hline
\end{tabular}

ISS idiopathic short stature, IQ intelligence quotient, TAC total antioxidant capacity, TOS total oxidant status, OSI oxidative stress index ${ }^{*} P$ value $<0.05$

${ }^{* *} P$ value $<0.001$ 

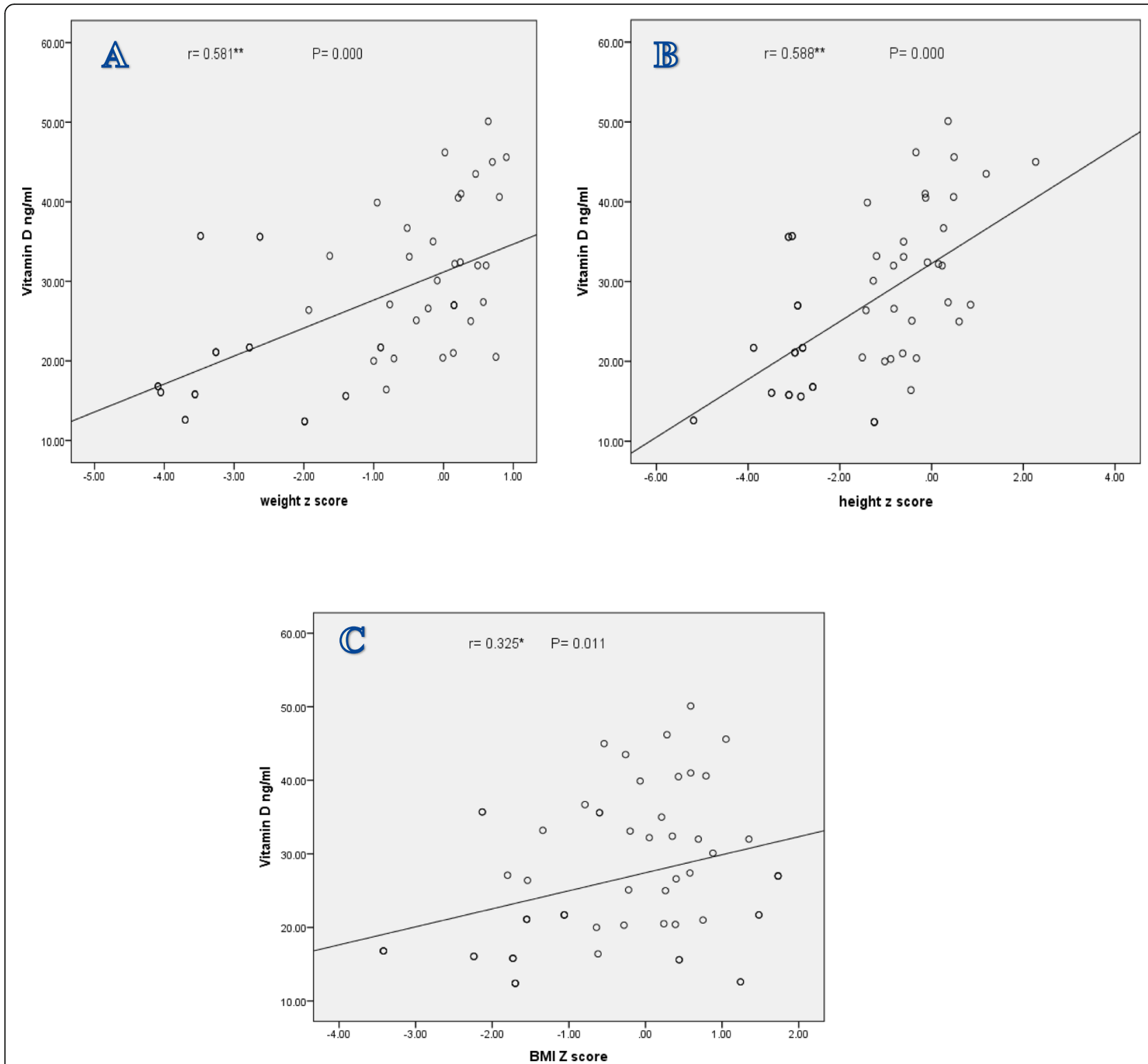

BMI: body mass index

Fig. 1 Correlation of vitamin D level ( $\mathrm{ng} / \mathrm{ml}$ ) with anthropometric measure Z scores (a) with weight Z score, (b) height Z score, and (c) BMl Z score

significantly lower vitamin D levels $(20.63 \mathrm{ng} / \mathrm{ml} \pm$ $7.35 \mathrm{SD})$ than $(32.18 \mathrm{ng} / \mathrm{ml} \pm 9.2 \mathrm{SD})$ the control group; a positive correlation between vitamin D level and all anthropometric measurements was detected.

In early life, vitamin D is essential for normal neuronal development; vitamin $\mathrm{D}$ regulates the expression of calcium-binding proteins and L-type voltagesensitive calcium channels, which play important roles in intracellular calcium balance. Vitamin D regulates the expression of neuron growth factor (NGF), neurotrophin-3 (NT-3), neurotrophin-4 (NT-4), and glial cell-derived neurotrophic factors. Additionally, the existence of vitamin $\mathrm{D}$ metabolic enzymes in addition to the VDR in the central nervous system suggests its participation in the cognitive functioning process [34]. Yates et al. [35] in an animal study revealed that rats born to vitamin D3-deficient mothers had marked brain alterations with some disabilities in early life, including learning and memory problems, with some evidence of increased lateral ventricle volume and altered neural expression of genes involved in dopamine and glucocorticoid-related pathways [35]. 
Table 4 Correlation between cognitive function parameters, Vitamin D level, and oxidative stress parameters in all studied children

\begin{tabular}{|c|c|c|c|c|c|}
\hline Variable & Statistics & Vitamin D & TAC & TOS & OSI \\
\hline \multirow[t]{2}{*}{ Non-verbal IQ } & Pearson correlation & $0.474^{* *}$ & $0.737^{* *}$ & 0.091 & $-0.654^{* *}$ \\
\hline & $P$ value & 0.000 & 0.000 & 0.487 & 0.000 \\
\hline \multirow[t]{2}{*}{ Verbal IQ } & Pearson correlation & $0.327^{*}$ & $0.691^{* *}$ & 0.251 & $-0.633^{* *}$ \\
\hline & $P$ value & 0.011 & 0.000 & 0.053 & 0.000 \\
\hline \multirow[t]{2}{*}{ Full-scale IQ } & Pearson correlation & $0.446^{* *}$ & $0.769^{* *}$ & 0.177 & $-0.714^{* *}$ \\
\hline & $P$ value & 0.0000 & 0.000 & 0.177 & 0.000 \\
\hline \multirow[t]{2}{*}{ Fluid reasoning } & Pearson correlation & $0.346^{* *}$ & $0.697^{* *}$ & 0.128 & $-0.722^{* *}$ \\
\hline & $P$ value & 0.007 & 0.000 & 0.330 & 0.000 \\
\hline \multirow[t]{2}{*}{ Knowledge } & Pearson correlation & $0.363^{* *}$ & $0.691^{* *}$ & $0.299^{*}$ & $-0.311^{*}$ \\
\hline & $P$ value & 0.004 & 0.000 & 0.020 & 0.015 \\
\hline \multirow[t]{2}{*}{ Quantitative reasoning } & Pearson correlation & $0.350^{* *}$ & $0.615^{* *}$ & $0.272^{*}$ & $-0.498^{* *}$ \\
\hline & $P$ value & 0.006 & 0.000 & 0.036 & 0.000 \\
\hline \multirow[t]{2}{*}{ Visuospatial } & Pearson correlation & $0.340 * *$ & $0.644^{* *}$ & 0.147 & $-0.720^{* *}$ \\
\hline & $P$ value & 0.008 & 0.000 & 0.263 & 0.000 \\
\hline \multirow[t]{2}{*}{ Working memory } & Pearson correlation & $0.504^{* *}$ & $0.653^{* *}$ & -0.053 & $-0.729^{* *}$ \\
\hline & $P$ value & 0.000 & 0.000 & 0.687 & 0.000 \\
\hline \multirow[t]{2}{*}{ Vitamin D } & Pearson correlation & & $0.546^{* *}$ & 0.041 & $-0.317^{*}$ \\
\hline & $P$ value & & 0.000 & 0.757 & 0.014 \\
\hline \multirow[t]{2}{*}{ TAC } & Pearson correlation & $0.546^{* *}$ & & 0.212 & $-0.623^{* *}$ \\
\hline & $P$ value & 0.000 & & 0.104 & 0.000 \\
\hline \multirow[t]{2}{*}{ TOS } & Pearson correlation & 0.041 & 0.212 & & $0.366^{* *}$ \\
\hline & $P$ value & 0.757 & 0.104 & & 0.004 \\
\hline \multirow[t]{2}{*}{ OSI } & Pearson correlation & $-0.317^{*}$ & $-0.623^{* *}$ & $0.366^{* *}$ & \\
\hline & $P$ value & 0.014 & 0.000 & 0.004 & \\
\hline
\end{tabular}

IQ intelligence quotient, TAC total antioxidant capacity, TOS total oxidative stress, OSI oxidative stress index

${ }^{* *}$ Correlation is significant at the 0.01 level (2-tailed)

*Correlation is significant at the 0.05 level (2-tailed)

An adequate vitamin $\mathrm{D}$ level is necessary to preserve neurological function development and protect the adult brain [15]. Multiple studies have shown a correlation between vitamin D level and cognitive function decline in elderly persons, with an effect on brain health and memory [14, 36-40], but few studies have evaluated this effect in children. Nassar et al. [41] stated that the vitamin D level was significantly lower in children with delayed school achievement, with a positive correlation between vitamin D level and Wechsler Intelligence Scale values for Children. Another cross-section study by Liu et al. [32] conducted on 563 children $(9.5 \pm 1.6$ years) from 6 areas of China, showed that serum vitamin D concentration was positively associated with the intelligence score. In the current study, cognitive function parameters of ISS children were within the average range of IQ classifications, but non-verbal IQ, full-scale IQ, fluid reasoning, knowledge, and working memory were significantly lower than those in the control group, with a positive correlation between vitamin $\mathrm{D}$ level and all cognitive function parameters.

Vitamin D also has an antioxidant effect that controls the process of detoxification in the brain by regulating the activity of $\gamma$ glutamyl transpeptidase [42], and multiple studies have demonstrated the presence of an association between vitamin D level, TOS, and antioxidant capacity in various diseases [43, 44]. In this current study, serum levels of TAC showed statistically significantly higher levels among healthy children than among children with ISS, with a positive correlation between vitamin $\mathrm{D}$ and TAC and a positive correlation between TAC and all cognitive function parameters in the studied children, but we could not find an association between vitamin $\mathrm{D}$ and TOS without any significant difference in serum levels of TOS between the two studied groups, which was in concordance with Wang et al. [45] whose results did not manifest a clear link between vitamin $\mathrm{D}$ status and oxidative stress markers in the 
absence of obesity, chronic disease, or advanced age. This finding may explain why all children included had no detectable chronic obesity.

\section{Limitations}

Brain imaging studies such as magnetic resonance image (MRI) because of limited financial resources for the exclusion of associated brain disorders may affect cognitive function parameters.

\section{Conclusion}

Vitamin D deficiency is highly associated with ISS and additional stunted growth in those children; vitamin D deficiency is also linked to decreasing antioxidant capacity and decreasing cognitive function parameters. Recommendations for continuous screening of vitamin D levels in all age groups to ensure normal physical and mental development in children and further prospective studies after correcting vitamin D levels to assess changes in growth and cognitive functions are needed.

\section{Abbreviations \\ BA: Bone age; BMI: Body mass index; EDTA: Ethylene diamine tetraacetic acid; ELISA: Enzyme-linked immunosorbent assay; IQ: Intelligence quotient; ISS: Idiopathic short stature; GH: Growth hormone; NGF: Neuron growth factor; NT-3: Neurotrophin-3; NT-4: Neurotrophin-4; OSI: Oxidative Stress Index; TAC: Total antioxidant capacity; TOS: Total oxidative stress; VDR: Vitamin D receptors; Z score: Standard deviation scores}

\section{Acknowledgements}

We greatly honored to express our thanks and deepest gratitude to our colleagues at the Pediatric Endocrinology Clinic of Qena University Hospital, South Valley University, Egypt, and to the staff at the department of medical physiology for their great help and support. Finally, we would like to extend our thanks and our gratitude to all the patients and their families, without their cooperation, no work can be done.

\section{Authors' contributions}

OA contributed to the conception and design of the study, drafting of article, analysis and interpretation of data, and final approval of the version to be published. HS shared in putting study design, psychological and cognitive assessment of the studied population, collection of data, analysis and interpretation of data writing the manuscript, and final approval of the version to be published. HA shared in laboratory work of the study, analysis and interpretation of data, and final approval of the version to be published. LA helped in the collection of data, analysis and interpretation of data, and final approval of the version to be published. All authors read and approved the final manuscript.

\section{Funding}

There was no funding received.

\section{Availability of data and materials}

All data generated and analyzed during this study are available from the corresponding author upon request.

\section{Ethics approval and consent to participate}

All participants' parents were informed about the aim of our study and written informed consent was obtained from parents after approval of the Ethical committee of Qena Faculty of Medicine, South Valley University. The Ethics committee reference numbers: 02/18

\section{Consent for publication}

Not applicable

\section{Competing interests}

The authors declare that they have no competing interests.

\section{Author details}

${ }^{1}$ Department of Medical Physiology, Faculty of Medicine, Assiut University, Assiut, Egypt. ²Department of Pediatrics, Faculty of Medicine, South Valley University, Qena, Egypt. ${ }^{3}$ Department of Medical Physiology, Faculty of Medicine, South Valley University, Qena, Egypt.

Received: 31 July 2019 Accepted: 29 January 2020

Published online: 16 March 2020

\section{References}

1. Holick MF, Chen TC (2008) Vitamin D deficiency: a worldwide problem with health consequences. Am. J. Clin. Nutr. 87(4):1080S-1086S

2. Laird E, Ward M, Mc Sorley E et al (2010) Vitamin D and bone health; Potential Mechanisms. Nutrients 2(7):693-724

3. Koo W, Walyat N (2013) Vitamin D and skeletal growth and development. Curr Osteoporos Rep. 11(3):188-193. https://doi.org/10.1007/s11914-0130156-1

4. Eisman JA, Bouillon R (2014) Vitamin D: direct effects of vitamin D metabolites on bone: lessons from genetically modified mice. Bonekey Rep. 3:499

5. Goltzman D (2018) Functions of vitamin D in bone. Histochem Cell Biol. 149(4):305-312

6. Cohen P, Rogol AD, Deal CL (2008) Consensus statement on the diagnosis and treatment of children with idiopathic short stature: a summary of the Growth Hormone Research Society, the Lawson Wilkins Pediatric Endocrine Society, and the European Society for Paediatric Endocrinology Workshop. J Clin Endocrinol Metab. 93(11):4210-4217

7. Pedicelli S, Peschiaroli E, Violi E et al (2009) Controversies in the Definition and Treatment of Idiopathic Short Stature (ISS). J Clin Res Pediatr Endocrinol. 1(3):105-115

8. Topor LS, Feldman HA, Bauchner H et al (2010) Variation in methods of predicting adult height for children with idiopathic short stature. Pediatrics 126:938

9. El-Rassi R, Baliki G, Fulheihan GE (2009) Vitamin D status in Middle East and Africa. American University of Beirut Medical Center, Department of Internal Medicine, Beirut, Lebanon

10. Palacios C, Gonzalez L (2014) Is vitamin D deficiency a major global public health problem? J. Steroid Biochem. Mol. Biol 144 Pt A:138-145

11. Cashman K, Dowling K, Škrabáková Z et al (2016) Vitamin D deficiency in Europe: pandemic? Am J Clin Nutr. 103(4):1033-1044

12. DeLuca GC, Kimball SM, Kolasinski J et al (2013) The role of vitamin D in nervous system health and disease. Neuropathol. Appl. Neurobiol. 39:458-484

13. Alzain WI, Altowairqi MM, Alalawi DK et al (2018) The Correlation between Vitamin D and Cognition. Egypt J Hosp Med. 70(6):1047-1055

14. Soni M, Kos K, Lang IA et al (2012) Vitamin D and cognitive function. Scand J Clin Lab Invest Suppl. 243:79-82. https://doi.org/10.3109/00365513.2012. 681969

15. Somma CD, Scarano E, Barrea L et al (2017) Vitamin D and Neurological Diseases: An Endocrine View. Int J Mol Sci. 18(11):2482

16. Physical status: the use and interpretation of anthropometry (1995) Report of a WHO Expert Committee. WHO Technical Report Series No. 854. World Health Organization, Geneva

17. Greulich WW, Pyle SI (1976) Radiographic atlas of skeletal development of the hand and wrist. Stanford University Press, Stanford

18. Roid GH (2003) Stanford-binet intelligence scales, fifth edition (sb:v). Can J Sch Psychol. 19:235-244

19. Desoky T, Hassan MH, Fayed HM et al (2017) Biochemical assessments of thyroid profile, serum 25-hydroxycholecalciferol and cluster of differentiation 5 expression levels among children with autism. Neuropsychiatr Dis Treat. 13:2397-2403

20. Hashemi S, Amani R, Cheraghian B (2017) Association of serum vitamin D and total antioxidant capacity levels with stress and anxiety in young female students. Iran J Psychiatry Behav Sci. 11(2):e7790

21. Erel O (2005) A new automated colorimetric method for measuring total oxidant status. Clin Biochem 38:1103-1111

22. Lee EJ, Moon JS, Ko JS et al (2017) Effect of the Baseline Vitamin D Level on Growth Outcome in Pediatric Crohn Disease. Pediatr Gastroenterol Hepatol Nutr. 20(1):41-46 
23. Lee YA, Kim JY, Kang MJ et al (2013) Adequate vitamin D status and adiposity contribute to bone health in peripubertal nonobese children. J. Bone Miner. Metab. 31:337-345

24. Xiong F, Yang F, Yang SF et al (2014) Relationship between serum 25hydroxyvitamin $\mathrm{D}$ and bone mineral density in children under 7 years old. Zhongguo Dang Dai Er Ke Za Zhi. 16:883-886

25. Fu Y, Hu Y, Qin Z et al (2016) Association of serum 25-hydroxyvitamin D status with bone mineral density in 0-7 year old children. Oncotarget. 7(49): 80811-80819

26. Ganmaa D, Stuart JJ, Sumberzul N et al (2017) Vitamin D supplementation and growth in urban Mongol school children: Results from two randomized clinical trials. PLoS One. 12(5):e0175237

27. Munns CF, Simm PJ, Rodda CP et al (2012) Incidence of vitamin D deficiency rickets among Australian children: an Australian Paediatric Surveillance Unit study. Med J Aust. 196:466-468

28. Zhu Z, Zhan J, Shao J et al (2012) High prevalence of vitamin D deficiency among children aged 1 month to 16 years in Hangzhou, China. BMC Public Health 12:126

29. Roh YE, Kim BR, Choi WB et al (2016) Vitamin D deficiency in children aged 6 to 12 years: single center's experience in Busan. Ann Pediatr Endocrinol Metab. 21(3):149-154

30. Bindusha S, Riaz I, Sujith KR, Lalitha K (2017) The vitamin D status in 6-14 Year Old Children Attending Tertiary Care Teaching Hospital in South India. Int J Cur Res Rev. 9(11):53-58

31. Mokhtar RR, Holick MF, Sempértegui F et al (2018) Vitamin D status is associated with underweight and stunting in children aged 6-36 months residing in the Ecuadorian Andes. Public Health Nutr. 21(11):1974-1985

32. Liu Y, Li X, Zhao A et al (2018) High Prevalence of Insufficient Vitamin D Intake and Serum 25-Hydroxyvitamin D in Chinese School-Age Children: A Cross-Sectional Study. Nutrients. 10(7):822

33. Miguel D (2018) Relationship between vitamin D, calcium, protein, fruits and vegetables and bone health in children with type 1 diabetes mellitus. Bone Health in Children with Type 1 Diabetes Mellitus. Endocrinol Diabetes Obes 1(2):1

34. Zong L, Chu P, Huang P et al (2017) Effect of vitamin D on the learning and memory ability of FGR rat and NMDA receptor expression in hippocampus. Exp Ther Med. 14(1):581-586

35. Yates NJ, Tesic D, Feindel KW et al (2018) Vitamin D is crucial for maternal care and offspring social behaviour in rats. J Endocrinol. 237:73-85

36. Llewellyn DJ, Lang IA, Langa KM et al (2010) Vitamin D and risk of cognitive decline in elderly persons. Arch Intern Med. 170(13):1135-1141. https://doi. org/10.1001/archinternmed.2010.173

37. Amraei M, Mohamadpour R, Moayeri A et al (2017) Vitamin D and its association with memory and learning: A systematic review and metaanalysis. Biomed Res 28(17):7427-7433

38. Anjum I, Jaffery S, Fayyaz M et al (2018) The role of vitamin D in brain health: a mini literature review. Cureus. 10(7):e2960. https://doi.org/10.7759/ cureus.2960

39. Aghajafari F, Pond D, Catzikiris N et al (2018) Quality assessment of systematic reviews of vitamin D, cognition and dementia. BJPsych Open. 4(4):238-249

40. Beydoun M, Hossain S, Fanelli-Kuczmarski M et al (2018) Vitamin D status and intakes and their association with cognitive trajectory in a longitudinal study of urban adults. J Clin Endocrinol Metab. 103(4):1654-1668

41. Nassar MF, Amin DA, Hamed Al (2012) Vitamin D status and scholastic achievement in middle age childhood. J Egypt Soc Parasitol. 42(2):349-358

42. Gezen-Ak D, Dursun E, Yilmazer S (2014) The effect of vitamin D treatment on nerve growth factor (NGF) release from hippocampal neurons. Noro Psikiyatr Ars. 51(2):157-162. https://doi.org/10.4274/npa.y7076

43. Baser H, Can U, Baser S et al (2015) Serum total oxidant/anti-oxidant status, ischemia-modified albumin and oxidized-low density lipoprotein levels in patients with vitamin D deficiency. Arch Endocrinol Metab. 59(4):318-324

44. Lee WC, Mokhtar SS, Munisamy S et al (2018) Vitamin D status and oxidative stress in diabetes mellitus. Cell Mol Biol (Noisy-le-grand). 64(7):60-69

45. Wang EW, Siu P, Pang MY et al (2017) Vitamin D deficiency, oxidative stress and antioxidant status: only weak association seen in the absence of advanced age, obesity or pre-existing disease. Br J Nutr. 118(1):11-16. https://doi.org/10.1017/S000711451700188X

\section{Publisher's Note}

Springer Nature remains neutral with regard to jurisdictional claims in published maps and institutional affiliations.

\section{Submit your manuscript to a SpringerOpen ${ }^{\circ}$ journal and benefit from:}

- Convenient online submission

- Rigorous peer review

- Open access: articles freely available online

- High visibility within the field

- Retaining the copyright to your article

Submit your next manuscript at $\boldsymbol{\nabla}$ springeropen.com 